\title{
Cryopreservation of human colorectal carcinomas prior to xenografting
}

\author{
Michael Linnebacher*1, Claudia Maletzki ${ }^{1}$, Christiane Ostwald², Ulrike Klier ${ }^{1}$, Mathias Krohn¹, Ernst Klar ${ }^{1}$ and \\ Friedrich Prall2
}

\begin{abstract}
Background: Molecular heterogeneity of colorectal carcinoma (CRC) is well recognized, forming the rationale for molecular tests required before administration of some of the novel targeted therapies that now are rapidly entering the clinics. For clinical research at least, but possibly even for future individualized tumor treatment on a routine basis, propagation of patients' CRC tissue may be highly desirable for detailed molecular, biochemical or functional analyses. However, complex logistics requiring close liaison between surgery, pathology, laboratory researchers and animal care facilities are a major drawback in this. We here describe and evaluate a very simple cryopreservation procedure for colorectal carcinoma tissue prior to xenografting that will considerably reduce this logistic complexity.

Methods: Fourty-eight CRC collected ad hoc were xenografted subcutaneously into immunodeficient mice either fresh from surgery ( $N=23$ ) or after cryopreservation ( $N=31$; up to 643 days).

Results: Take rates after cryopreservation were satisfactory (71\%) though somewhat lower than with tumor tissues fresh from surgery (74\%), but this difference was not statistically significant. Re-transplantation of cryopreserved established xenografts $(N=11)$ was always successful. Of note, in this series, all of the major molecular types of CRC were xenografted successfully, even after cryopreservation.
\end{abstract}

Conclusions: Our procedure facilitates collection, long-time storage and propagation of clinical CRC specimens (even from different centres) for (pre)clinical studies of novel therapies or for basic research.

\section{Background}

The last decade has witnessed a tremendous progress in understanding the molecular pathology and the pathogenesis of colorectal carcinoma (CRC). Chromosomal as well as microsatellite instability and the $\mathrm{CpG}$ island methylator phenotype have been defined as major molecular pathogenetic mechanisms, giving rise to the main molecular classes of CRC [1,2]; and genome wide mutational analysis have shown that per individual cancer a limited number of signal transduction pathways are dysregulated by "driver" mutations in some (typically about 15) from a set of about 80 so-called candidate cancer genes $[3,4]$.

In the wake of this, targeted therapies for CRC are beginning to enter the clinics, EGF-receptor blockade (with the pre-requisite of K-Ras mutational analysis)

* Correspondence: michael.Linnebacher@med.uni-rostock.de

1 Department of General Surgery, Division of Molecular Oncology and Immunotherapy, Clinic for Surgery, Schillingallee 35, 18057 Rostock, Germany Full list of author information is available at the end of the article being the first already to be used more generally among these $[5,6]$. It may be expected for the near future that patient's tumor tissues, besides being subject to traditional histopathological examination, will be used for various additional molecular testings. While some of these can be done with conventional paraffin-embedded material, some will require frozen tumor tissue. But, conceivably, more elaborate molecular analyses or even functional tests eventually may be desirable, and for these analyses at least xenograft tumors may be prime choice [7-9].

However, xenografting as a routine will pose considerable logistical difficulties as technical expertise of different fields (surgery, pathology, molecular biology and animal care) must be brought together. Clearly, separating location and occasion when the tumor specimen accrues, the molecular analyses are done, and the engraftings are performed would rigorously reduce this logistical complexity. In addition, at least for research 
purposes, it would allow preselection of tumor specimens with desired molecular features in advance of the technically demanding xenografting procedures.

We here report an easy and effective method to store CRC tissue by cryopreservation for use in xenografting at a later date. Specifically, we aimed to explore feasibility and success rate in a consecutive series of CRCs collected ad hoc, comparing xenografting of tumor tissue fresh from surgery with xenografting after cryopreservation. In addition, we demonstrate that cryopreservation of established xenograft tumors for re-xenografting is also feasible. And finally, we show that a balanced distribution of the different molecular classes of CRCs will be obtained.

\section{Methods}

\section{Tumor specimen collection and cryopreservation}

Resection specimens of primary tumors $(\mathrm{N}=48$; primary CRCs without previous chemo-or radiotherapy) were received fresh from surgery. Tumor tissue cubes (ca. $3 \times 3$ $\times 3 \mathrm{~mm}$ ) were cut from the deep invasive parts with a sterile scalpel blade.

Mirror blocks for cryostat sections were prepared from the adjacent parts of the tumours. Alternatively, xenograft tumors were removed under sterile conditions and pieces were taken from the peripheral parts of the tumors. Again, adjacent tumour tissues were used for cryostat sections. Typically, 4 tumor pieces were transferred into sterile cryo-tubes (greiner-bio-one, Frickenhausen, Germany) in $1.5 \mathrm{ml}$ freezing medium (foetal calf serum containing 10\% DMSO), sealed in a Freezing Container (Nalgene, Rochester, NY, USA), and placed immediately at $-80^{\circ} \mathrm{C}$. Until transplantation tubes were kept at $80^{\circ} \mathrm{C}$ (for a maximum of 6 weeks) or, after overnight cooling, transferred into liquid nitrogen (for longer storage periods). For xenografting, cryopreserved tumor pieces were thawed at $37^{\circ} \mathrm{C}$. Prior informed consent was obtained in written from all patients, and all procedures were approved by the Ethics Committee of the University of Rostock (reference number II HV 43/2004) in accordance with generally accepted guidelines for the use of human material.

\section{Tumor xenografting}

Tumor xenograftings were done by one of the following approaches: (I) xenografting of primaries on the day of surgery $(n=23)$; (II) xenografting of primaries after cryopreservation ( $\mathrm{n}=31$ ); and (III) re-transplantation of xenografts after cryopreservation $(n=11)$. Tumor pieces were implanted subcutaneously uni-or bilaterally into the flanks of six to eight week old female mice under ether anaesthesia for a short period of time. We used NODSCID (NOD.CB17-Prkdcscid/J in cases of HROC24 to HROC46 and nude mice (NMRI nu/nu) for the subsequent xenograftings. As assessed by cryostat sections from the mirror blocks, there was seen an area fraction of $30-80 \%$ of viable tumour in the tissues used for xenografting. The numbers of mice receiving grafts and the numbers of grafts for each animal are given for each individual tumor in Table 1. Mice were kept in the animal facilities of the medical faculty of the University of Rostock and maintained in specified pathogen-free conditions. Animals were exposed to 12-h light/12-h darkness cycles and standard food and water including antibiotics (Co-trimoxazol) ad libitum. Their care and housing were in accordance with guidelines as put forth by the German Ethical Committee and the Guide for the Care and Use of Laboratory Animals (Institute of Laboratory Animal Resources, National Research Council; NIH Guide, vol.25, no.28, 1996). Growth of tumours to volumes of 1 $1.5 \mathrm{~cm}^{3}$ was taken as evidence of successful xenografting, and the animals were then sacrificed for collection of tumour tissues for further studies.

\section{Morphological and molecular studies}

Dissections and histopathological examination of the primary tumors were done according to standard protocols for surgical pathology reports of CRCs [10], and additional staging information was compiled from patients' clinical charts. Primary tumors and xenografts were embedded in paraffin, and $4 \mu \mathrm{m} H \& E$ sections were obtained as well as $\beta$-catenin and MLH1 and MSH2 immunostainings.

The molecular analyses were done as previously published in detail [2]. Briefly, the Bethesda panel of microsatellite markers was used to test for microsatellite instability, chromosomal instability was assessed by DNA-flow cytometry and $\mathrm{LOH}$ analyses with various dinucleotide markers (D5S1385, D5S346 (5q21); D8S1734, D8S1771, NEFL (8p21); D9S942, D9S1748 (9p21); D17S1832, D17S250 (17p23); D18S70 (18q23)), and mutation analyses of the APC gene as well as the KRas and B-Raf genes were done. Finally, DNA-methylation was assessed by the MethyLight technology with the marker panel originally published by Ogino et al. and modified by us [2]. Based on these molecular data, tumors in this series were classified as sporadic standard type CRC (spStdCRC), sporadic high-degree microsatellite instable CRC (spMSI-H), hereditary non-polyposis CRC-type (HNPCC-type), or CpG island methylator phenotype CRC (CIMP-type)

\section{Verification of human origin of the xenograft tumors}

A human specific PCR was performed by amplification of a portion of the human mitochondrial cytochrome b gene as previously described [11]. Briefly, the reaction mixture $(25 \mu \mathrm{l})$ contained $25 \mathrm{ng}$ of gDNA, $0.1 \mathrm{mM}$ of each primer (L15674: TAGCAATAATCCCCATCCTCCATATAT, H15782: ACTTGTCCAATGATGGTAAAAGG), $200 \mu \mathrm{M}$ 
Table 1: Details of xenograftings and outcomes.

\begin{tabular}{|c|c|c|c|}
\hline Tumor-ID & Fresh & Cryopreserved & Days frozen \\
\hline $\mathrm{HROC} 24$ & $M 1(+) ; M 2(-) ; M 3^{*}$ & & \\
\hline HROC26 & M1(-); M2(-); M3(-) & & \\
\hline HROC29 & $\mathrm{M} 1(+) ; \mathrm{M} 2(+) ; \mathrm{M} 3(-)$ & & \\
\hline HROC32 & $\mathrm{M} 2(+) ; \mathrm{M}^{*}$ & & \\
\hline HROC33 & M1(-); M2(-); M3(-) & & \\
\hline HROC37 & M1(-); M2(-) & & \\
\hline HROC38 & M1(-); M2(-) & & \\
\hline HROC39 & $\mathrm{M} 1(+) ; \mathrm{M} 2(+)$ & & \\
\hline HROC40 & $\mathrm{M} 1(+) ; \mathrm{M} 2(+)$ & & \\
\hline HROC45 & M1(-); M2(-) & & \\
\hline HROC46 & $\mathrm{M} 1(+) ; \mathrm{M} 2(+)$ & & \\
\hline HROC48 & & M1(-;-); M2(-;-);M3(+;+); M4(+;-) & $161 / 643$ \\
\hline HROC50 & & $\mathrm{M} 1(+;+) ; \mathrm{M} 2(-;+)$ & 120 \\
\hline HROC51 & & M1(-;-); M2(-;-) & 117 \\
\hline HROC52 & & M1(-;-); M2(-;-) & 94 \\
\hline HROC53 & & $\mathrm{M} 1(-;+) ; \mathrm{M} 2(-;-)$ & 84 \\
\hline HROC54 & & M1(-;-); M2(-;+) & 64 \\
\hline HROC55 & & M1(-;-); M2(-;-);M3(-;+); M4(-;-) & $6 / 489$ \\
\hline HROC56 & $\mathrm{M} 1(-) ; \mathrm{M} 2(-)$ & & \\
\hline HROC57 & $\mathrm{M} 1(+) ; \mathrm{M} 2(-)$ & & \\
\hline HROC59 & $\mathrm{M} 1(+;+) ; \mathrm{M} 2(-;+)$ & & \\
\hline HROC60 & $\mathrm{M} 1(-;+) ; \mathrm{M} 2(-;-)$ & & \\
\hline HROC61 & & M1(-;-); M2(-;-) & 58 \\
\hline HROC62 & & M1(-;-); M2(+;-) & 51 \\
\hline
\end{tabular}


Table 1: Details of xenograftings and outcomes. (Continued)

\begin{tabular}{|c|c|c|c|}
\hline HROC63 & M1(-;+); M2(-;-) & M1(-;-); M2(-;-) & 88 \\
\hline HROC64 & & M1(+;-); M2(-;-) & 78 \\
\hline HROC65 & M1(+;-); M2(-;-) & M1(+;-); M2(-;-) & 13 \\
\hline HROC66 & & M1(-;-); M2(-;-) & 47 \\
\hline HROC67 & & M1(-;-); M2(-;-) & 42 \\
\hline HROC68 & M1(+;+);M2(+;+) & $\mathrm{M} 1(-;+) ; \mathrm{M} 2(-;+)$ & 38 \\
\hline HROC69 & $\mathrm{M} 1(+;+) ; \mathrm{M} 2(+;+)$ & M1(-;-); M2(-;-) & 28 \\
\hline HROC70 & M1(-;-); M2(-;+) & M1(-;+); M2(-;-) & 27 \\
\hline HROC71 & & $\mathrm{M} 1(+;+) ; \mathrm{M} 2(-;+)$ & 27 \\
\hline HROC72 & & $\mathrm{M} 1(+;+) ; \mathrm{M} 2(-;-)$ & 240 \\
\hline HORC73 & & M1(-;-); M2(-;-) & 238 \\
\hline HROC74 & & $\mathrm{M} 1(+;+) ; \mathrm{M} 2(-;-)$ & 230 \\
\hline HROC75 & & $\mathrm{M} 1(-;+) ; \mathrm{M} 2(+;+)$ & 223 \\
\hline HROC78 & & M1(+;+); M2(-;-) & 188 \\
\hline HROC80 & & M1(-;+); M2(-;-) & 119 \\
\hline HROC81 & & M1(-;-); M2(-;+) & 118 \\
\hline HROC82 & & $\mathrm{M} 1(+;+) ; \mathrm{M} 2(-;-)$ & 118 \\
\hline HROC83 & & M1(-;-); M2(-;-) & 87 \\
\hline HROC84 & & M1(-;+); M2(-;-) & 73 \\
\hline HROC85 & $\mathrm{M} 1(-;+) ; \mathrm{M} 2(+;+)$ & & \\
\hline HROC86 & $\mathrm{M} 1(-;+)$ & & \\
\hline HROC87 & & M1(-;+);M2(-;+) & 9 \\
\hline HROC88 & & $\mathrm{M} 1(+;+) ; \mathrm{M} 2(-;+)$ & 7 \\
\hline HROC89 & M1(-;-); M2(+;-) & $\mathrm{M} 1(+;+)$ & 103 \\
\hline
\end{tabular}

$M$ denotes mice xenografted, the outcome is given in parentheses as index + or index - One index is given for uni-and two indices for bilateral xenografts. * animals died due to problems with anaesthesia. Underlined: repetition of the xenografting procedure. 
dNTPs, $1 \times$ standard reaction buffer and $0.1 \mathrm{U}$ Taq DNA polymerase (Bioron, Ludwigshafen, Germany). PCR was performed in a standard thermal cycler for 40 cycles of 30 $\mathrm{s}$ at $96^{\circ} \mathrm{C}, 40 \mathrm{~s}$ at $59^{\circ} \mathrm{C}$, and $1 \mathrm{~min}$ at $72^{\circ} \mathrm{C}$. Products were separated on a $1 \%$ agarose gel and results were scored positive with the appearance of a band of $157 \mathrm{bp}$.

\section{Statistics}

All data were entered into a computerized data bank (Statistical Package for the Social Sciences, SPSS version 13.0). Testing for significance of cross-tabulated data was done by two-sided Fisher's exact T-test. The criterion for significance was taken to be $\mathrm{p}<0.05$.

\section{Results}

Overall, 48 primary CRCs were collected for these xenografting experiments. 47 were adenocarcinomas, and 1 tumor was a large cell neuroendocrine carcinoma (HROC 57). Information on histological and molecular types as well as staging information and patient characteristics are summarized in Table 2.

Xenografting of 23 tumors fresh from surgery was successful in 17 cases (74\% take). By comparison, 31 tumors were xenografted after cryopreservation for 6 to 643 days, and this was successful in 22 cases (71\% take - summarized in Table 2), Thus, there was not observed a statistically significant difference in the overall success rates between fresh $(n=17 / 23)$ and cryopreserved $(n=22 / 31)$ samples ( $\mathrm{p}=0.815$, Fisher's exact T-test). As most animals received bilateral xenografts comparison between total numbers of fresh and cryopreserved xenografts could be made. Again, the difference was not statistically significant although a trend to reduced success after cryopreservation was observed $(n=34 / 68 ; 50 \%$ fresh, $n=40$ / 130; $31 \%$ cryopreserved, $\mathrm{p}=0,098$; Table 1 ). In two cases, where xenografts did not grow successfully after cryopreservation, enough frozen tumor pieces were left to repeat xenografting at a much later date (643 and 489 days), this time with success (animals M3 and M4 of HROC48 and HROC55; Table 1, underlined).

For 6 of the 48 tumors, sufficient material was available to attempt both xenografting of tumor tissue fresh from surgery and xenografting of tumor tissues after cryopreservation (13 to 103 days). This was successful for all the tumor tissues xenografted fresh from surgery, and for 4 cases of cryopreserved tissues (67\%; Table 2). Details on the xenograftings and their outcomes are given in Table 1.

Re-transplantation of xenograft tumors after cryopreservation was attempted for 11 tumors, and this could be carried out successfully in all cases. These tumor tissues were from passages 2 to 8 and had been cryopreserved for 56 to 455 days (Table 3). In terms of grafts, 47 of 54 grafts were accepted (87\%; Table 3$)$.
As expected, histologically the xenograft tumors closely resembled their primaries (Figure 1). PCR studies amplifying part of the human mitochondrial cytochrome $b$ gene gave further proof of the human origin of these tumors (data not shown). Furthermore, the molecular analyses revealed that xenografting could be carried out successfully for all the molecular types of CRC without any evident bias. Specifically, xenografts were obtained for 27 spStdCRC, 6 spMSI-H tumors, 2 HNPCC-type tumors, and 3 CIMP tumors.

Generally, xenografting was well tolerated by the animals. No signs of superinfection or suppuration were seen in any of the cases and consequently, no death from infection occurred. This was even true for those cases where tumor samples contained bacteria as judged from infections observed in parallel cultures in vitro (data not shown). In this series, we never observed metastases.

\section{Discussion}

In this study, we were able to show that tumor tissue from primary CRC surgical resection specimens can be cryopreserved and successfully xenografted into mice even after prolonged periods of storage (up to 643 days). Even though take rates with this procedure seem to be lower than with tumor tissue used fresh from surgery $(71 \%$ overall take for cryopreserved vs. $74 \%$ overall take for fresh tissues), this difference was not of statistical significance. Besides, it is still satisfactory and compares favourably to xenograft take rates reported by other groups [1215]. Not unlikely, take rates could even be improved by increasing the number of implantations or by Matrigelsoaking of tumor pieces before xenografting as suggested by Fujii et al. as well as by Sorio et al. $[14,15]$. The latter group was also the first to report a successful cryopreservation technique for pancreatic cancers [14]. As a technically very simple method, cryopreservation of CRC tumor tissue prior to xenografting as reported here may be quite appealing to both clinical and basic researchers alike for the following reasons:

(1) Cryopreservation before xenografting considerably reduces logistic constraints. If tumor tissue is xenografted fresh from surgery the work-flow is very complex. At first liaison will have to be made with the surgical colleagues for the resection specimen to be brought to the pathology department. From there the tumor tissue is handed over to the xenograft-team, often past usual work-hours; and presuming in any case that there are animals ready for use in the breeding-facilities on the day of surgery. Obviously, putting a break into this will make the procedure much easier.

(2) Cryopreservation before xenografting facilitates collection of large numbers of tumor specimens, even from different centres. This may be important for pre-clinical studies addressing e.g. the effects of targeted therapies as 
Table 2: Data of colorectal carcinomas used for xenografting experiments and overall results of outcomes.

\begin{tabular}{|c|c|c|c|c|c|c|}
\hline Tumor-ID & Age/Gender & Site* & TNM-Stage & Molecular type $^{\dagger}$ & Fresh & Cryo \\
\hline $\mathrm{HROC24}$ & $98 / \mathrm{m}$ & Right colon & G2T2NOMO & spMSI & Success & $\mathrm{ND}^{\ddagger}$ \\
\hline HROC26 & $60 / \mathrm{m}$ & Left colon & G3T4N2M1 & spStd & Failure & ND \\
\hline HROC29 & $59 / \mathrm{m}$ & Right colon & G3T3N2M1 & HNPCC & Success & ND \\
\hline HROC32 & $82 / f$ & Right colon & G2T4N2M1 & spStd & Success & ND \\
\hline HROC33 & $70 / f$ & Left colon & G2T3N1M0 & spStd & Failure & ND \\
\hline HROC37 & $77 / \mathrm{m}$ & Right colon & G3T2NOMO & ND & Failure & ND \\
\hline HROC38 & $67 / f$ & Right colon & G2T3NOMO & spStd & Failure & ND \\
\hline HROC39 & $69 / \mathrm{m}$ & Right colon & G3T4NOMO & spStd & Success & ND \\
\hline HROC40 & $69 / \mathrm{m}$ & Left colon & G3T3N1M0 & CIMP-H & Success & ND \\
\hline HROC45 & $52 / \mathrm{m}$ & Right colon & G3T4NOMO & ND & Failure & ND \\
\hline HROC46 & $66 / \mathrm{m}$ & Right colon & G3T3N0M1 & spStd & Success & ND \\
\hline HROC48 & $68 / \mathrm{m}$ & Right colon & G3T2N1M0 & spMSI & ND & Success \\
\hline HROC50 & $67 / f$ & Right colon & G2T4NOMO & spMSI & ND & Success \\
\hline HROC51 & $70 / \mathrm{m}$ & Left colon & G3T4N2M1 & spStd & ND & Failure \\
\hline HROC52 & $55 / f$ & Left colon & G2T2NOMO & spStd & ND & Failure \\
\hline HROC53 & $72 / f$ & Right colon & G3T3NOMO & spMSI & ND & Success \\
\hline HROC54 & $63 / f$ & Left colon & G2T3N2M0 & spStd & ND & Success \\
\hline HROC55 & $81 / f$ & Right colon & G3T2NOMO & spMSI & ND & Success \\
\hline HROC56 & $70 / \mathrm{m}$ & Right colon & G1T3NOMO & ND & Failure & ND \\
\hline HROC57 & $43 / \mathrm{m}$ & Right colon & G3T3N2M1 & $N A^{\S}$ & Success & ND \\
\hline HROC59 & $76 / \mathrm{m}$ & Right colon & G2T3N1M1 & spStd & Success & ND \\
\hline HROC60 & $71 / \mathrm{m}$ & Right colon & G2T2NOMO & CIMP-H & Success & ND \\
\hline HROC61 & $57 / \mathrm{m}$ & Rektum & G3T3NOMO & spStd & ND & Failure \\
\hline HROC62 & $84 / f$ & Right colon & G3T4N2M0 & spStd & ND & Success \\
\hline
\end{tabular}


Table 2: Data of colorectal carcinomas used for xenografting experiments and overall results of outcomes. (Continued)

\begin{tabular}{|c|c|c|c|c|c|c|}
\hline HROC63 & $81 / f$ & Left colon & G2T4NOM0 & spStd & Success & Failure \\
\hline HROC64 & $71 / \mathrm{m}$ & Left colon & G2T2NOMO & spStd & ND & Success \\
\hline HROC65 & $73 / f$ & Right colon & G3T3N2M1 & spStd & Success & Success \\
\hline HROC66 & $75 / \mathrm{m}$ & Rektum & G2T3N2M0 & spStd & ND & Failure \\
\hline HROC67 & $54 / \mathrm{m}$ & Left colon & G2T3N1M0 & spStd & ND & Failure \\
\hline HROC68 & $84 / m$ & Left colon & G2T4N2M0 & spStd & Success & Success \\
\hline HROC69 & $62 / \mathrm{m}$ & Right colon & G3T3N0M1 & spStd & Success & Failure \\
\hline HROC70 & $65 / f$ & Right colon & G3T4N1M0 & spStd & Success & Success \\
\hline HROC71 & $52 / \mathrm{m}$ & Right colon & G2T3NOMO & HNPCC & ND & Success \\
\hline $\mathrm{HROC72}$ & $61 / \mathrm{m}$ & Right colon & G2T3N2M1 & & ND & Success \\
\hline HORC73 & $69 / m$ & Left colon & G2T3NOMO & & ND & Failure \\
\hline $\mathrm{HROC74}$ & $80 / \mathrm{m}$ & Left colon & G2T4NOMO & spStd & ND & Success \\
\hline HROC75 & $58 / \mathrm{m}$ & Left colon & G2T3NOMO & spStd & ND & Success \\
\hline HROC78 & $75 / \mathrm{m}$ & Right colon & G3T3NOMO & CIMP-H & ND & Success \\
\hline HROC80 & $72 / m$ & Right colon & G2T3N2M1 & & ND & Success \\
\hline HROC81 & $21 / f$ & Right colon & G3T4N0M1 & spStd & ND & Success \\
\hline HROC82 & $62 / \mathrm{m}$ & Right colon & G2T3NOMO & & ND & Success \\
\hline HROC83 & $85 / f$ & Right colon & G2T3N1M1 & & ND & Failure \\
\hline HROC84 & $88 / f$ & Left colon & G2T3NOMO & spStd & ND & Success \\
\hline HROC85 & $65 / m$ & Rektum & G2T3NOMO & spStd & Success & ND \\
\hline HROC86 & $79 / f$ & Left colon & G2T3N1M0 & spStd & Success & ND \\
\hline HROC87 & $76 / f$ & Left colon & G3T3N0M0 & spMSI & ND & Success \\
\hline HROC88 & $69 / f$ & Right colon & G2T3N1M0 & & ND & Success \\
\hline HROC89 & $80 / \mathrm{m}$ & Rektum & G2T3NOM1 & spStd & Success & Success \\
\hline
\end{tabular}

* Right colon (coecum to splenic flexure), left colon (descending colon and sigmoid), Rektum. $\uparrow$ Abbreviations for molecular types of colorectal carcinomas. ‡ ND - not determined/not done. § NA - not applicable. 
Iimdbacher et al. BMC Cancer 2010, 10:362

Table 3: Successful re-xenografting after cryopreservation.

\begin{tabular}{lccc}
\hline Tumor-ID & Passage number & Days frozen & Success rate by grafts \\
\hline HROC24 & 3 & 148 & $2 / 2$ \\
\hline HROC29 & $6-8$ & $147,182,189$ & $7 / 10$ \\
\hline HROC32 & 5 & 168 & $4 / 4$ \\
\hline HROC39 & 2 & 164 & $4 / 4$ \\
\hline HROC40 & 2 & 191 & $4 / 4$ \\
\hline HROC46 & 2 & 455 & $7 / 8$ \\
\hline HROC50 & 2,3 & 120,168 & $5 / 6$ \\
\hline HROC53 & 2,3 & 84,168 & $6 / 6$ \\
\hline HROC54 & 2 & 56 & $2 / 2$ \\
\hline HROC59 & 2 & 119 & $2 / 2$ \\
\hline HROC71 & 2 & & $4 / 4$ \\
\hline
\end{tabular}

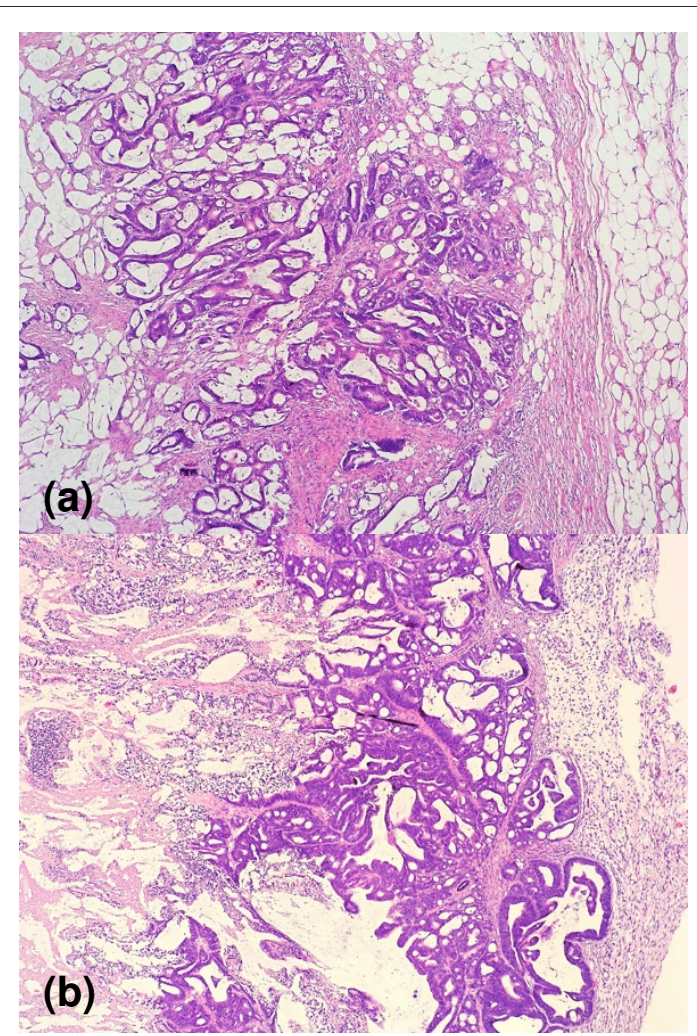

Figure 1 Tumor morphology. Examples of (a) primary tumor (HROC50) and (b) its xenograft. Compared to its primary, the tumor architecture, growth pattern, and cytological features are well preserved in the xenograft tumor. it has been shown that human tumor xenografts can be used for prediction, especially when panels are used [16,7-9]. Conceivably, even, cryopreservation could allow post hoc analysis and propagation in xenografts of those patients' tumor tissue that have responded (or not responded) to specific therapies.

(3) Cryopreservation before xenografting allows preselection of frozen tumor samples out of a larger collection. This drastically reduces time and resources needed to obtain individual xenografts of a desired molecular type. Important to note in this respect is, apparantly by our procedure none of the major molecular types of CRC would be excluded.

(4) Finally, we observed that cryopreservation of established xenografts of CRC samples for later re-transplantation is particularly successful $(100 \%$ take in terms of cases and $87 \%$ in terms of grafts). This may be interesting if low-passage xenografts are desired, as it has been shown that similar to cell lines xenografts may acquire additional mutations and changes in the karyotype [17,12]; and it is very convenient in relieving laboratories from the necessity of continuous passaging. Moreover, it will greatly facilitate the exchange of well-characterized models between different institutions.

\section{Conclusions}

In the presented study we demonstrate the feasibility of xenografting of clinical CRC specimens after a transient cryopreservation step. A statistical comparison of the 
success rates with and without cryopreservation revealed no significant difference. In addition, we show that cryopreservation of established xenograft tumors for re-xenografting is particularly feasible. And finally, we show that a balanced distribution of the different molecular classes of colorectal carcinomas will be obtained using this procedure. These findings may have immediate impact on the improvement of preclinical drug testing procedures. To the best of our knowledge; this has never been done for CRC.

\section{Abbreviations}

CIMP-H: CpG island methylator phenotype; CRC: colorectal carcinoma; HNPCCtype: hereditary non-polyposis-type CRC; spMSI-H: sporadic high-degree microsatellite instable CRC; spStdCRC: sporadic standard type CRC

\section{Competing interests}

The authors declare that they have no competing interests.

\section{Authors' contributions}

$M L$ conceived of the study, participated in its design and coordination, data analysis, and writing of the manuscript. CM performed the statistics and helped to draft the manuscript. CO carried out most of the molecular analyses. UK helped to analyze and interpret the data. MK performed the human-specific PCR. EK reviewed the manuscript. FP performed the morphological analyses and participated in the interpretation of the data, and the writing of the manuscript. All authors read and approved the final manuscript.

\section{Acknowledgements}

The authors kindly thank Karin Gerber and Kathrin Sievert-Küchenmeister for their excellent technical assistance in animal care. This work was substantially supported by grant number 2006/A29 from the Else-Kröner Fresenius Stiftung to ML and EK and by grant number 108446 "Norddeutsche Tumorbank kolorektales Karzinom" from Deutsche Krebshilfe.

\section{Author Details}

1 Department of General Surgery, Division of Molecular Oncology and Immunotherapy, Clinic for Surgery, Schillingallee 35, 18057 Rostock, Germany and 2Institute of Pathology; Strempelstr. 14, 18055 Rostock, University of Rostock, Rostock, Germany

Received: 13 January 2010 Accepted: 8 July 2010

Published: 8 July 2010

\section{References}

1. Jass JR: Molecular heterogeneity of colorectal cancer: Implications for cancer control. Surg Oncol 2007, 16:7-9.

2. Ostwald C, Linnebacher M, Weirich V, Prall F: Chromosomally and microsatellite stable colorectal carcinomas without the CpG island methylator phenotype in a molecular classification. Int J Oncol 2009, 35:321-7.

3. Wood LD, Parsons DW, Jones S, et al:: The genomic landscapes of human breast and colorectal cancers. Science 2007, 318:1108-13.

4. Velculescu VE: Defining the blueprint of the cancer genome. Carcinogenesis 2008, 29:1087-91.

5. Freeman DJ, Juan T, Reiner M, et al:: Association of K-ras mutational status and clinical outcomes in patients with metastatic colorectal cancer receiving panitumumab alone. Clin Colorectal Cancer 2008, 7(3):184-90

6. Amado RG, Wolf $M$, Peeters $M$, et al:: Wild-type KRAS is required for panitumumab efficacy in patients with metastatic colorectal cancer. $J$ Clin Oncol 2008, 26:1626-34.

7. Kerbel RS: Human tumor xenografts as predictive preclinical models for anticancer drug activity in humans: better than commonly perceivedbut they can be improved. Cancer Biol Ther 2003, 2:134-9.

8. Sausville EA, Burger AM: Contributions of human tumor xenografts to anticancer drug development. Cancer Res 2006, 66:3351-4.
9. Voskoglou-Nomikos T, Pater JL, Seymour L: Clinical predictive value of the in vitro cell line, human xenograft, and mouse allograft preclinical cancer models. Clin Cancer Res 2003, 9:4227-39.

10. Fielding LP, Arsenault PA, Chapuis PH, et al.: Clinocpatholgoical staging for colorectal cancer: an International Documentation System (IDS) and an Interantional Comprehensive Anatomical Terminology (ICAT). J Gastroenterol Hepatol 1991, 6:325-44

11. Matsuda H, Seo Y, Kakizaki E, Kozawa S, Muraoka E, Yukawa N: Identification of DNA of human origin based on amplification of human-specific mitochondrial cytochrome b region. Forensic Sci int 2005, 152:109-14.

12. Bocsi J, Zalatnai A: Establishment and long-term xenografting of human pancreatic carcinomas in immunosuppressed mice: changes and stability in morphology, DNA ploidy and proliferation activity. J Cancer Res Clin Oncol 1999, 125:9-19.

13. Cui JH, Krüger $U$, Vogel I, et al:: Intact tissue of gastrointestinal cancer specimen orthotopically transplanted into nude mice. Hepatogastroenterology 1998, 45:2087-96.

14. Sorio C, Bonora A, Orlandini S, et al.: Successful xenografting of cryopreserved primary pancreatic cancers. Virchows Arch 2001, 438:154-8.

15. Fujii E, Suzuki M, Matsubara K, et al.: Establishment and characterization of in vivo human tumor models in the NOD/SCID/gamma(c)(null) mouse. Pathol Int 2008, 58:559-67.

16. Bellett AJ, Younghusband HB: Spontaneous, mutagen-induced and adenovirus-induced anchorage independent tumorigenic variants of mouse cells. J Cell Physiol 1979, 101:33-47.

17. Reyes G, Villanueva A, García C, et al:: Orthotopic xenografts of human pancreatic carcinomas acquire genetic aberrations during dissemination in nude mice. Cancer Res 1996, 56:5713-9.

Pre-publication history

The pre-publication history for this paper can be accessed here: http://www.biomedcentral.com/1471-2407/10/362/prepub

doi: $10.1186 / 1471-2407-10-362$

Cite this article as: Linnebacher et al., Cryopreservation of human colorectal carcinomas prior to xenografting BMC Cancer 2010, 10:362

\section{Submit your next manuscript to BioMed Central and take full advantage of:}

- Convenient online submission

- Thorough peer review

- No space constraints or color figure charges

- Immediate publication on acceptance

- Inclusion in PubMed, CAS, Scopus and Google Scholar

- Research which is freely available for redistribution 